Check for updates

Cite this: Chem. Commun., 2021, 57,11049

Received 31st May 2021,

Accepted 23rd September 2021

DOI: $10.1039 / \mathrm{d} 1 \mathrm{cc} 02871 \mathrm{e}$

rsc.li/chemcomm

\section{Effects of X-ray, electron beam and gamma irradiation on PE/EVOH/PE multilayer film properties $\dagger$}

\author{
Nina Girard-Perier, (D) a Magalie Claeys-Bruno, ${ }^{b}$ Sylvain R. A. Marque, (D) *c \\ Nathalie Dupuy, ${ }^{* b}$ Fanny Gaston ${ }^{a}$ and Samuel Dorey (D) *a
}

To increase sterilization capacity, X-ray and e-beam irradiation modalities are more and more attractive for the indutrial sterilization of heathcare products (medical devices and biopharmaceutical goods). However, no study comparing these different techniques are available concerning multi-layer films. Thus, with the PE/EVOH/ PE multilayer film as a model, we show that, whatever the modality of irradiation, the thermal properties are not significantly changed as shown by DSC, and, as such, the physical and mechanical properties of this material are also expected to behave similarly. On the other hand, chemical properties such as oxidation ability are strikingly modified, i.e., the same oxidation level for $\mathrm{X}$-ray and $\gamma$-irradiation and twice weaker for e-beam irradiation.

Among the various techniques of sterilization, e.g., ethylene oxide, steam, and $\gamma$-irradiation, the latter might be one of the most attractive due to its safety aspects, versatility, and easy procedures for applications in fields such as the food, biopharmaceutical and medical device industries. ${ }^{1-5}$ Currently, gamma irradiation is the most common irradiation modality used for the sterilization of medical devices and biopharmaceutical products while two other irradiation modalities are emerging: electron beam (referred to as e-beam or $\beta$-beam) and X-ray irradiation. ${ }^{6}$ Whatever the modality of ionizing radiation used, it would modify the physical-mechanical-tribological and chemical properties of the polymers. A great number of articles have reported on the impact of gamma irradiation on polymers ${ }^{7-10}$ while only a few report on another irradiation modality such as $\mathrm{X}$-ray irradiation. ${ }^{11,12}$ Few investigations $\mathrm{s}^{13,14}$ have been focused on the comparison of the effects of these irradiation modalities

\footnotetext{
${ }^{a}$ Sartorius Stedim FMT S.A.S, Z.I. Les Paluds, Avenue de Jouques CS91051,

Aubagne Cedex 13781, France. E-mail: samuel.dorey@sartorius.com

${ }^{b}$ Aix Marseille Univ, Avignon Univ, CNRS, IRD, IMBE, Marseille, France.

E-mail: Nathalie.dupuy@univ-amu.fr

${ }^{c}$ Aix Marseille Univ, CNRS, ICR, case 551, Marseille 13397, France.

E-mail: sylvain.marque@univ-amu.fr

$\dagger$ Electronic supplementary information (ESI) available: Experimental details and

Fig. S1. See DOI: 10.1039/d1cc02871e
}

on the properties of biopharmaceutical and medical devices and, to the best of our knowledge, none of them concern polyethylene $(\mathrm{PE}) /$ ethylene vinyl alcohol $(\mathrm{EVOH}) / \mathrm{PE}$ multilayer films. Some studies ${ }^{11,15-18}$ have been devoted to investigating the effects of low energy X-ray on polymers, which is presently out of our scope. A few articles report about the comparison of the effects of $\gamma$-irradiation and electron beam irradiation on the mechanical properties of polypropylene. Fintzou et al. ${ }^{19}$ highlighted, for instance, that $\gamma$-irradiation of polypropylene had a greater effect on its mechanical and thermal properties (i.e., decrease in load and extension at break and smaller decrease in melting point for $\gamma$-irradiated samples) than electron-beam irradiation. Hassan et al. ${ }^{20}$ showed that the degradation of the properties of high crystallinity polypropylene caused by gamma irradiation was higher than that caused by e-beam irradiation. Badia et al. ${ }^{21}$ compared the effects of $\gamma$-irradiation and e-beam irradiation on high density polyethylene and found no changes in its shelf life. In 2007, Croonenborghs et al. ${ }^{22}$ reported on the effect of high energy X-ray and $\gamma$-irradiations on the mechanical properties of different polymers, including polyethylene. They compared these two irradiation processes at the same dose rate $\left(7.5 \mathrm{kGy} \mathrm{h}^{-1}\right)$. Both modalities of irradiation have very similar effects on the mechanical properties of polyethylene. Importantly, by setting the same dose rate for both irradiation modalities, they studied the impact of the different radiation energy distributions for these two irradiation modalities on polymer properties. Even though e-beam, X-ray and $\gamma$-irradiation modalities display similarities regarding the main mechanism of interaction of radiation with matter, they could induce differences in material properties, when the radiation energy distribution and especially the dose rate vary. ${ }^{23}$

In sharp contrast to the works cited, our approach aims to be as close as possible to the industrial conditions of irradiations as well as for the materials used. Thus, the impact of three irradiation sources - X-ray, e-beam and ${ }^{60} \mathrm{Co}-\gamma$ - is investigated under industrial conditions (see experimental section in the ESI†). Therefore, neither the impact of dose rate, nor the 
radiation energy distribution are investigated here. Single use bags made up of $\mathrm{PE} / \mathrm{EVOH} / \mathrm{PE}$ multilayer film and commonly used in the biopharmaceutical field have been selected as a model. The effects of $\gamma$-irradiation on the physical/mechanical/ chemical properties of this multilayer film have been previously studied thoroughly using different techniques, ${ }^{24-32}$ assuming an irradiation dose at $c a .50 \mathrm{kGy}$ as the worst case for $\gamma$-irradiation to overlap the routine irradiation dose range (i.e., 25-45 kGy), and at ca. $70 \mathrm{kGy}$ as a worst case for the X-ray irradiation. The changes in the transition temperatures are determined by differential scanning calorimetry (DSC) as a probe of material degradation. The generation of reactive species such as peroxides and peracids due to radical post reactivity is probed by the oxidation of methionine (mimicking the oxidation of proteins) monitored by high performance liquid chromatography (HPLC). The presence of long-lived radicals is monitored by electron spin resonance (ESR).

The radicals are monitored by ESR analysis of the film material after 10 and 20 days for $\gamma$ - and e-beam irradiation, respectively (Fig. 1).

A three-peak signal is observed accordingly as previously reported (see the ESI $\dagger$ ). ${ }^{33}$ The radical species disappear after 45 and 60 days for samples gamma irradiated at $59 \mathrm{kGy}$ and $106 \mathrm{kGy}$, respectively. Radical species present in the sample e-beam irradiated at 51 kGy disappear after 45 days. This sample has the same behavior as the sample $\gamma$-irradiated at 59 kGy. Thus, $\gamma$-irradiation and e-beam irradiation afford roughly the same amount of radicals and decay with similar kinetics for doses 59 and 51 kGy, respectively. $\ddagger$ For X-ray irradiated samples, no radicals were detected at 80 days post X-ray irradiation. Unfortunately, ESR experiments were not performed at earlier times due to COVID restrictions, marring any discussion on the presence and the quantity of the radicals generated.

The melting peak temperatures of $\mathrm{PE}$ and EVOH are similar whatever the irradiation modality and almost equivalent to the values reported for non-sterilized materials (Fig. 2) meaning that their thermal properties are unchanged. Therefore, the

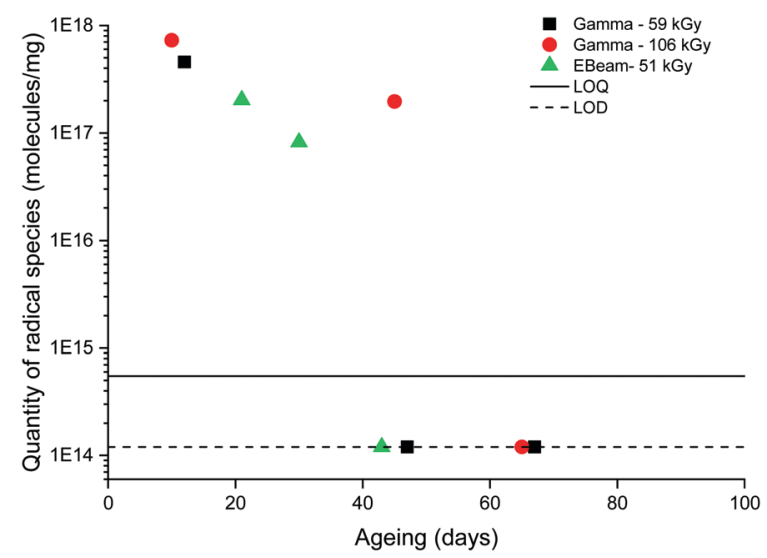

Fig. 1 Quantity of radical species in PE/EVOH/PE multilayer film over time in a semi-log scale. Solid line for the quantification limit (LOQ) at $5.5 \times 10^{14}$ molecules per $\mathrm{mg}$; dashed line for detection limit (LOD) at $1.2 \times 10^{14}$ molecules per $\mathrm{mg}$.
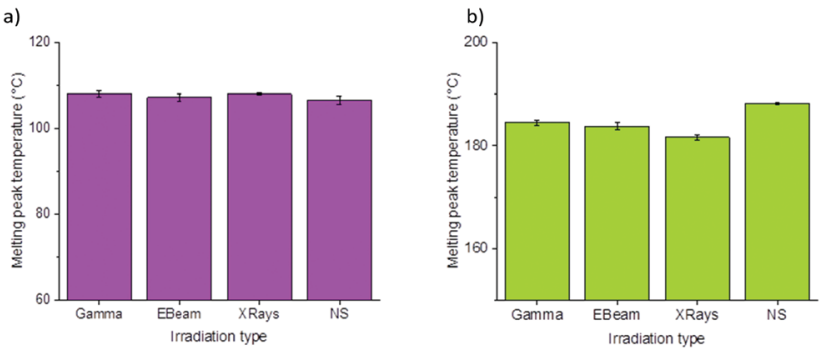

Fig. 2 Melting peak temperatures measured by DSC 3 months after irradiation (50 kGy for gamma irradiation, 51 kGy for electron beam and 68 kGy for X-ray) for the PE layer (a, purple) and EVOH layer (b, green) used in the PE/EVOH/PE multilayer film. NS is for non-sterile (non-irradiated) samples. A thermogram of the electron beam irradiated sample at $50 \mathrm{kGy}$ is shown in Fig. S2, ESI $\dagger$

structure of the materials is not significantly altered and their mechanical and physical properties are not dramatically modified, as already reported for $\gamma$-irradiation of EVA/EVOH/ EVA films. ${ }^{24-27,30,31,34}$

Fig. 3 displays the oxidation potential, after ageing for 3 months, of sample bags sterilized by X-ray, e-beam or $\gamma$-irradiation measured by the HPLC-detection of the methionine sulfoxide from the solution stored for 10 days in bags as already reported (see the $\mathrm{ESI} \dagger)^{35}$

$\mathrm{X}$-ray and $\gamma$-irradiation processes generate roughly the same quantity of methionine sulfoxide $(0.88 \pm 0.12 \mu \mathrm{M}$ and $0.74 \pm 0.02 \mu \mathrm{M}$, respectively), twice as high as the quantity observed for the e-beam irradiated sample $(0.44 \pm 0.01 \mu \mathrm{M})$. The difference between the quantities of methionine sulfoxide for $\gamma$-irradiated samples and e-beam irradiated samples is statistically significant (Student test), with a $p$-value $<5 \%$ ( $p$-value $=0.036)$. The same observation holds for e-beam irradiated samples and X-ray irradiated samples, with a $p$-value $<1 \%(p$-value $=0.002)$.

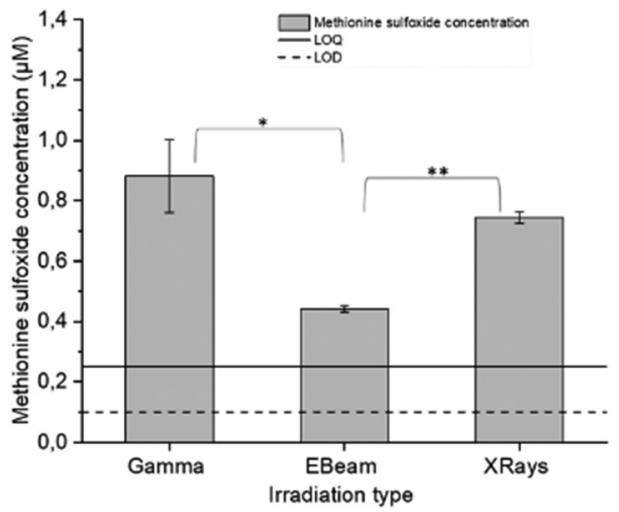

Fig. 3 HPLC analyzed methionine sulfoxide concentration $(\mu M)$ in solution stored for 10 days in bags. Irradiation doses were $50 \mathrm{kGy}$ for $\gamma$-irradiation, 51 kGy for e-beam irradiation and 68 kGy for X-ray irradiation. Solid line for Limit of quantification (LOQ) and dashed line for limit of detection (LOD). * means that the difference between 2 values is statistically significant and $p$-value $<5 \%$ ( $p$-value $=0.036$ for gamma/electron beam). $* *$ means that the difference between 2 values is statistically significant and $p$-value $<1 \%$ ( $p$-value $=0.002$ for electron beam $/ X$-ray). 
At this stage, it is assumed that the processes involved in X-ray and $\gamma$-irradiation are likely to be the same and to release the same amount and type of oxidant species. For e-beam irradiation, it is likely that the oxidant species and their processes of generation are the same, but a smaller quantity of oxidant is generated. $\S$

$\mathrm{PE} / \mathrm{EVOH} / \mathrm{PE}$ film oxidation is due to the generation of peracids $\mathrm{RCOOOH}$. The formation of the latter is due to the reaction between hydrogen peroxide $\mathrm{H}_{2} \mathrm{O}_{2}$ generated from the EVOH layer ${ }^{35}$ and organic acids generated by the PE layers. ${ }^{24}$ As ESR analysis shows that the same amount of radicals is generated in the EVOH layer for both e-beam and $\gamma$-irradiations (Fig. 1), and as their decays are similar, it is assumed that the same amount of $\mathrm{H}_{2} \mathrm{O}_{2}$ is generated. On the other hand, due to the experimental conditions, it was not possible to detect the radicals generated in PE layers, and consequently, the type of irradiation may play a role in the generation of organic acids from PE layers leading to the difference observed in the level of oxidation between e-beam and $\gamma$-irradiations. Nevertheless, an effect of the dose rate on the radicals generated in the $\mathrm{PE}$ layers as well as on the stability of peracids or organic acids cannot be discarded straightforwardly as the irradiation conditions were not controlled, on purpose (vide supra and $\mathrm{ESI} \dagger$ ).

These observations on oxidation level depending on the type of irradiation highlight nicely the interest in performing experiments in conditions as close as possible to industrial processes, which makes challenging the analysis of results. It supports a multitechnique and a multi-level approach ${ }^{1}$ - product, macromolecular and molecular levels - of the modifications of such materials under irradiation providing valuable data to end-users. Experiments are thus performed in industrial conditions and analyses are performed subsequently to decipher molecular processes which are at the grounds of observations at the product level.

Hence, depending on the biopharmaceutical applications envisioned, e-beam irradiation might have some advantages over X-ray and $\gamma$ irradiations concerning physical/mechanical/ chemical properties.

Thus, this first study evaluating the effects of X-ray, e-beam and $\gamma$-irradiations on the $\mathrm{PE} / \mathrm{EVOH} / \mathrm{PE}$ film reveals both very similar and different trends depending on the properties investigated. Therefore, more studies are in progress along the lines discussed above. ${ }^{1,35}$

This work has been funded by Sartorius.

\section{Conflicts of interest}

There are no conflicts to declare.

\section{References}

\$ As expected, non-sterilized films did not exhibit an ESR signal.

$\S$ It must be mentioned that the generation of oxidant depends also on the quantity of organic acids generated. pH-metry investigations are in progress for X-ray and electron beam irradiation.

1 S. Dorey, S. R. A. Marque, N. Dupuy, M. Murphy, L. Fifield, S. D. Pillai, M. Pharr, D. Staack and L. Nichols, An International Industry and
Academia Collaboration to Supplement Gamma Sterilization by X-ray and E-beam Technologies, in preparation.

2 P. M. Armenante and O. Akiti, in Chemical Engineering in the Pharmaceutical Industry: Active Pharmaceutical Ingredients, ed. D. J. Ende and M. T. Ende, Wiley, 1st edn, 2019.

3 S. Moondra, N. Raval, K. Kuche, R. Maheshwari, M. Tekade and R. K. Tekade, Dosage Form Design Parameters, Elsevier, 2018, pp. 467-519.

4 D. Darwis, Erizal, B. Abbas, F. Nurlidar and D. P. Putra, Macromol. Symp., 2015, 353, 15-23.

5 V. Komolprasert, Radiat. Phys. Chem., 2016, 129, 35-38.

6 BPSA Technical Guide, X-Ray Sterilization of Single-Use BioProcess Equipment, Part 1: Industry Need, Requirements \& Risk Evaluation, 2021, https://bpsalliance.org/technical-guides/.

7 K. Abdel Tawab, S. M. Ibrahim and M. M. Magida, J. Radioanal. Nucl. Chem., 2013, 295, 1313-1319.

8 A. Buttafava, G. Consolati, M. Mariani, F. Quasso and U. Ravasio, Polym. Degrad. Stab., 2005, 89, 133-139.

9 P. H. Kang and Y. C. Nho, Radiat. Phys. Chem., 2001, 9.

10 L. Montanari, M. Costantini, E. C. Signoretti, L. Valvo, M. Santucci, M. Bartolomei, P. Fattibene, S. Onori, A. Faucitano, B. Conti and I. Genta, J. Controlled Release, 1998, 56, 219-229.

11 M. Manfredini, D. Atzei, B. Elsener, A. Marchetti and A. Rossi, Surf. Interface Anal., 2003, 35, 294-300.

12 S. A. Nouh, H. A. El-Nabarawy, M. M. Abutalib and R. A. Bahareth, Eur. Phys. J.: Appl. Phys., 2013, 62, 30201.

13 L. S. Fifield, M. Pharr, D. Staack, S. D. Pillai, L. Nichols, J. McCoy, T. Faucette, T. T. Bisel, M. Huang, M. K. Hasan, L. Perkins, S. K. Cooley and M. K. Murphy, Radiat. Phys. Chem., 2021, 180, 109282.

14 L. S. Fifield, M. Pharr, D. Staack, S. D. Pillai, L. Nichols, J. McCoy, T. Faucette, T. T. Bisel, M. Huang, M. K. Hasan, L. Perkins, S. K. Cooley and M. K. Murphy, Radiat. Phys. Chem., 2021, 186, 109505.

15 T. Takahagi, Y. Nakayama, F. Soeda and A. Ishitani, J. Appl. Polym. Sci., 1990, 41, 1451-1458.

16 S. C. Graham, R. H. Friend, S. Fung and S. C. Moratti, Synth. Met., 1997, 84, 903-904.

17 F. M. F. Ng and K. N. Yu, Mater. Chem. Phys., 2006, 100, 38-40.

18 T. Coffey, S. G. Urquhart and H. Ade, J. Electron Spectrosc. Relat. Phenom., 2002, 122, 65-78.

19 A. T. Fintzou, M. G. Kontominas, A. V. Badeka, M. R. Stahl and K. A. Riganakos, Radiat. Phys. Chem., 2007, 76, 1147-1155.

20 M. M. Hassan, N. A. El-kelesh and A. M. Dessouki, Polym. Compos., 2008, 29, 883-889.

21 A. Badia and G. Duplâtre, Radiat. Phys. Chem., 1999, 54, 151-158.

22 B. Croonenborghs, M. A. Smith and P. Strain, Radiat. Phys. Chem., 2007, 76, 1676-1678.

23 W. Schnabel, Polymer Degradation - Principles and Practical Applications, Hanser, 1982.

24 S. Dorey, F. Gaston, N. Dupuy, M. Barbaroux and S. R. A. Marque, Eur. J. Pharm. Sci., 2018, 117, 216-226.

25 S. Dorey, F. Gaston, S. R. A. Marque, B. Bortolotti and N. Dupuy, Appl. Surf. Sci., 2018, 427, 966-972.

26 F. Gaston, N. Dupuy, S. R. A. Marque, D. Gigmes and S. Dorey, J. Appl. Polym. Sci., 2018, 135, 46114.

27 F. Gaston, N. Dupuy, S. R. A. Marque, M. Barbaroux and S. Dorey, Polym. Degrad. Stab., 2016, 129, 19-25.

28 F. Gaston, N. Dupuy, S. R. A. Marque, M. Barbaroux and S. Dorey, Radiat. Phys. Chem., 2016, 125, 115-121.

29 F. Gaston, N. Dupuy, S. R. A. Marque, M. Barbaroux and S. Dorey, Anal. Chim. Acta, 2017, 981, 11-23.

30 N. Girard-Perier, F. Gaston, N. Dupuy, S. R. A. Marque, L. Delaunay and S. Dorey, Food Packaging and Shelf Life, 2020, vol. 26, p. 100582.

31 S. Dorey, F. Gaston, N. Girard-Perier, N. Dupuy, S. R. A. Marque and L. Delaunay, J. Appl. Polym. Sci., 2020, 137, 49361.

32 S. Dorey, F. Gaston, N. Girard-Perier, N. Dupuy, S. R. A. Marque and L. Delaunay, Ind. Eng. Chem. Res., 2019, 58, 14115-14123.

33 G. Audran, S. Dorey, N. Dupuy, F. Gaston and S. R. A. Marque, Polym. Degrad. Stab., 2015, 122, 169-179.

34 N. Girard-Perier, M. Claeys-Bruno, S. R. A. Marque, N. Dupuy, F. Gaston and S. Dorey, Polymers, 2020, 12, 3024.

35 N. Girard-Perier, M. Claeys-Bruno, S. R. A. Marque, N. Dupuy, F. Gaston and S. Dorey, Monitoring of Peroxide in Gamma Irradiated PE Multilayer Film Using Methionine Probe, submitted. 